\title{
Safety Assessment of Aircraft Fuel Tank Access Cover under the Impact Load by Tire Fragments
}

\author{
Shile Yao ${ }^{1,2^{*}} \mathbb{D}$, Zhufeng Yue ${ }^{2}$, Xiaoliang Geng ${ }^{2}$ and Peiyan Wang ${ }^{2}$
}

\begin{abstract}
According to relevant airworthiness standards, the aircraft fuel tank access cover must withstand the impact by tire fragments, and minimize the penetration and deformation, which is critical for flight safety. To assess the safety of an aircraft fuel tank access cover subjected to tire fragments, a study of dynamic response was presented in this paper using the Finite element (FE) software ANSYS/LS-DYNA. To obtain the reliable mechanical characteristics of tire tread rubber, a series of material tests have been conducted. Then the proposed rubber material model is validated by comparing the numerical simulations with the experimental results of aluminium alloy plate impact. The simulation results indicate that the rubber fragment and alloy plate will undergo the largest deformation when impact angle is equal to $90^{\circ}$. Finally, the proposed FE model and modelling approaches are extended to the numerical simulation of a full-scale aircraft fuel tank access cover impact. The numerical simulations are carried out with impact velocity of 71.1 $\mathrm{m} / \mathrm{s}$ and impact angle of $40.5^{\circ}$. The simulation results indicate that the aluminium alloy by precision casting is more likely to rupture, and the middle region of the access cover is vulnerable to fragment impact. This research proposes a reliable rubber model applying to various strain rates. Considering the influence of impact regions, the dynamic response and various failure patterns of fuel tank access cover are acquired. The findings of this paper can be used to improve the future aircraft safety design.
\end{abstract}

Keywords: Dynamic response, Tire fragment, Aircraft fuel tank access cover, Impact, Safety

\section{Introduction}

Aircraft tires are the important equipment for aviation safety [1], which always play a key role in supporting aircraft weight and sliding on the ground [2]. Nevertheless, the probability of an accident caused by aircraft tires is very high [3]. The aircraft tire may release tire debris when in contact with the ground, which is a severe threat for the flight safety. According to the European Aviation Safety Agency (EASA) safety rules, the tire debris is likely to penetrate and open the fuel tank or fuel system structure located in the vulnerable zone. The rupture of fuel tank access or other structure of fuel system components may induce severe fuel leakage [4]. It is documented that

\footnotetext{
*Correspondence: 233313702@qq.com

${ }^{1}$ Department of Engineering Mechanics, Henan University of Science and Technology, Luoyang 471023, China

Full list of author information is available at the end of the article
}

a number of flight accidents are associated with high speed debris released during tire blowout [5]. In the Concorde supersonic aircraft accident (2000), the tire on Concorde's left main wheel bogie exploded, and a piece of tire debris hit the fuel tank, which caused a fuel leak and led to a fire [6]. Since then, the threat of tire debris has been focused on by researchers in aviation safety study.

The Federal Aviation Administration (FAA) airworthiness standards require that each fuel tank within the fuselage contour must be able to avoid rupture and to keep the amount of the fuel [7]. The fuel tank access covers must prevent loss of hazardous quantities of fuel in the normal and accident conditions. All the fuel tank covers located in the area where an impact may take place, must be analyzed or tested to minimize the damage by tire debris [8]. Consequently, it is of important significance to study the safety of the fuel access cover subjected to the impact load of tire fragment. 
At present, there have been enough studies on the dynamic characteristics of rubber material under impact loading. Ambriško et al. [9] analysed the tension load of rubber composite conveyor belts by impact dynamic testing, and the factors that significantly affect the value of the tension load are identified. Luo et al. [10] improved the classic hyperelastic models to predict complete loading-unloading response using energy dissipation approach, and proposed NFR (Natural Frequency Region) approach to simulate a dynamic impact event instead of using the usual viscoelastic methodology. Andrejiova et al. [11] focused on the damage of conveyor belts rubber, and carried out the analysis of the rubber samples damage significance using the logistic regression method in their study.

Furthermore, the study of tire fragment impact is relatively rare, with few studies in the literatures. Mines et al. [12] investigated the dynamic response of aluminium alloy plates under the impact of aircraft rubber tire fragments, in there study, tire fragments were fired at clamped aluminium alloy plates with speeds of up to $135 \mathrm{~m} / \mathrm{s}$ and at angles of $90^{\circ}, 60^{\circ}$, and $30^{\circ}$. Finite element analysis (FEA) is a very cost-effective computer simulation tool, which can solve such complex impact problem. Karagiozova and Mines [13] proposed a Finite Element model for a reinforced rubber material to simulate a tire fragment impact on a typical aircraft structure using the software LS-DYNA, the FE model was validated using the static and dynamic experimental data for the actual rubber material of tire tread. It can be found that many studies use a constitutive material model or hyperelastic model to describe rubber characteristics. In present paper, the rubber behavior is described by a simplified rubber model, which is defined by a group of stress-strain uniaxial curves with various strain rates. This rubber model is effective and reliable in dealing with various dynamic problems [14].

On the other hand, some researchers focus on the safety of fuel tank during various dynamic scenarios. In Zhang's study [15], FEA and impact test have done for two types of fuel tank access cover structures. Compared with the conclusion, they achieved more safety fuel tank access cover structures that was compliant the airworthiness standard. Wang et al. [16] simulated the impact process of aircraft fuel tank access by rubber fragment, using finite element software ANSYS/ LS-DYNA. Dynamic characteristics of several composite covering caps impacted by various projectiles were studied. Prus et al. [17] simulated a drop test of an elastic fuel tank reinforced with a polymer exoskeleton, and pointed out the potential of this design in aerospace applications. However, few researches involve the failure patterns of fuel tank access cover under tire fragment impact, which is critical on the safety of aircraft fuel system.

This paper mainly describes an investigation on an aircraft fuel tank access cover subjected to tire fragment impact for safety assessment. Several tests were carried out to get an accurate and reliable rubber model, including quasi-static and dynamic tests using electronic universal testing machine and drop hammer. Subsequently, the dynamic response of the aluminium alloy plate under the impact load by tire fragment was studied through numerical simulations, which were aimed to validate the numerical rubber model and the impact analysis method. The proposed rubber material model was then used in numerical simulations of full-scale fuel tank access cover subjected to larger tire fragment impact. Various impact locations and materials of access cover were considered. Finally, based on the numerical analyses results, some important conclusions were drawn. It is expected that the findings of present study can be useful in improvement of aviation safety.

\section{Experimental and Numerical Tire Material Testing}

Tread and sidewall are considered to be the main rubber parts of an aircraft tire, the tire fragments are usually assumed to be released from the tread area of the tire [4]. Hence tests and correlation are required for the accurate characterization of the tread rubber.

\subsection{Description of Rubber Material and FE Model}

Due to having the long chain molecule, rubber material usually presents a complicated mechanical characteristics which cannot be described by the linear elastic theory and has large deformations, plastic and viscoelastic properties [18-21]. As a typical hyperelastic material,the rubber can be defined by a stored energy function [2]. The characterization of rubber should be determined by various experimental data, so the key issue is to acquire a reliable material model which can provide good fit with the test data. It is of great importance to ensure that the numerical calculation can simulate the response of the rubber material. To get reliable and accurate characteristics of rubber material, many researchers did lots of works on fitting and comparison of rubber models with experimental data $[2,13,22,23]$.

ANSYS/LS-DYNA has many material models to define the rubber material, including Mooney-Rivlin, Frazer-Nash, Simplified Rubber Material, Hyperelastic and Yeoh model, etc [24]. Although these sophisticated material models are available in ANSYS/LS-DYNA to simulate rubber, the determination of material properties can be non-trivial and time consuming. The Simplified Rubber Material (SRM) model, which represented as "MAT_SIMPLIFIED_RUBBER was selected in present 
study. This rubber model is defined by one uniaxial load curve or by a group of uniaxial curves at various strain rates [24]. For SRM model, incompressibility is assumed. Ogden function is computed from uniaxial test results, so it is unnecessary to identify any parameter. "MAT_SIMPLIFIED_RUBBER will reproduce the uniaxial compression tests exactly, and no fit is done [25]. To acquire satisfactory simulation for the tread rubber, a series of tests were finished at various strain rates.

In SRM model, strain rate effects are considered through the linear viscoelasticity by a convolution integral of the form:

$$
\sigma_{i j}=\int_{0}^{t} g_{i j k l}(t-\tau) \frac{\partial \varepsilon_{k l}}{\partial \tau} \mathrm{d} \tau,
$$

or in terms of the second Piola-Kirchhoff stress, $\left\{S_{0}\right\}$, and Green's strain tensor, $\left\{S_{R T}\right\}$,

$$
S_{i j}=\int_{0}^{t} G_{i j k l}(t-\tau) \frac{\partial E_{k l}}{\partial \tau} \mathrm{d} \tau,
$$

where $g_{i j k l}(t-\tau)$ and $G_{i j k l}(t-\tau)$ are the relaxation functions for the different stress measures. This stress is added to the stress tensor determined from the strain energy functional [26].

\subsection{Material Correlation and Validation}

In present study, several quasi-static uniaxial compression tests have been carried out to acquire the hyperelastic characteristics of the rubber materials, as shown in Figure 1. According to ASTM D575-91 standard [27], the cylindrical rubber specimens were cut in accordance with a specified diameter-height ratio. The specimens, which have a height of $9 \mathrm{~mm}$ and diameter of $20 \mathrm{~mm}$, were taken only from the tire tread.

Using an electronic universal testing machine, the rubber specimens were compressed with three different strain rates: $0.001 \mathrm{~s}^{-1}, 0.01 \mathrm{~s}^{-1}$ and $1.00 \mathrm{~s}^{-1}$. The temperature of the testing room was maintained at $23 \pm 2$ ${ }^{\circ} \mathrm{C}$. The relative humidity of atmosphere was controlled to $50 \pm 6 \%$. The specimens to be tested were kept in this room for $4 \mathrm{~h}$ before the testing.

After measuring the dimensions of the test specimen, place the specimen between the platens of the test machine. During these tests, the continuous compressive force was applied on the specimen and the corresponding deflection was recorded at the same time, the force-displacement curves were used to describe the stress-strain properties of rubber materials.

To correlate the material FE model with test data, numerical simulations of these tests have been carried out in ANSYS/LS-DYNA. In the simulation, the density of rubber is assumed to be $1000 \mathrm{~kg} / \mathrm{m}^{3}$, Poisson

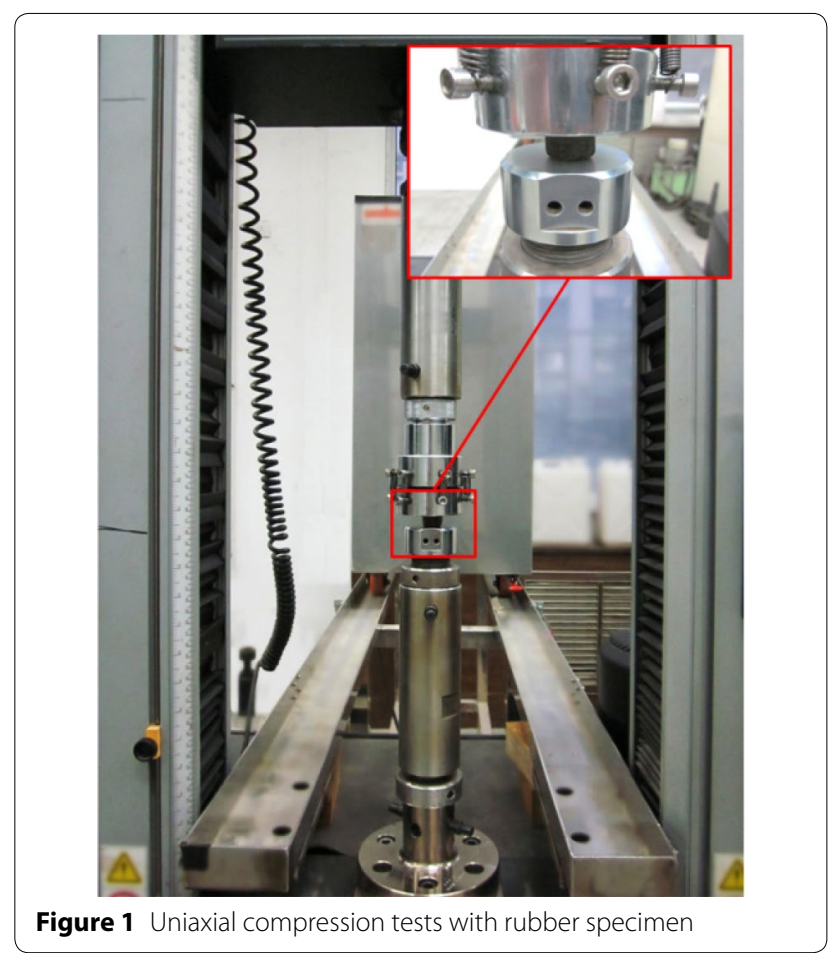

ratio is 0.495 . Firstly, with the initial boundary conditions applied, a same sized discrete model of the rubber specimen has been established, as shown in Figure 2(a). Solid elements with one integration point were chosen for large deformation analysis of the tire rubber material. This element is sufficient efficient and accurate, however, hourglass control is also needed in each case [14]. Secondly, a test prescribed motion was applied on the top surface of the specimen to simulate its uniaxial compression. Finally, the axial forces will be compared between simulations and test results for material correlation.

The force versus displacement curves acquired from numerical simulation and test data with different strain rates are shown in Figure 3(a). It can be seen that the curves from experimental and numerical tests have good agreement for various strain rate, and evident strain rate dependency can be noticed. The comparisons results show that the constitutive model selected can accurately describe the response of rubber specimen during compression with various strain rates. In addition, the test data of tire rubber with high strain rate $\left(5700 \mathrm{~s}^{-1}\right.$ and $3800 \mathrm{~s}^{-1}$ ) were acquired from dynamic split Hopkinson pressure bar test by Baranowski et al. [22].

The drop hammer was used to perform experimental tests with dynamic conditions. The aim of the dynamic experiments was to validate the rubber model under dynamic loading condition. The drop hammer has a weight of $5 \mathrm{~kg}$, the impact height is $2 \mathrm{~m}$, giving an energy of $100 \mathrm{~J}$. In these tests, the rubber specimens 

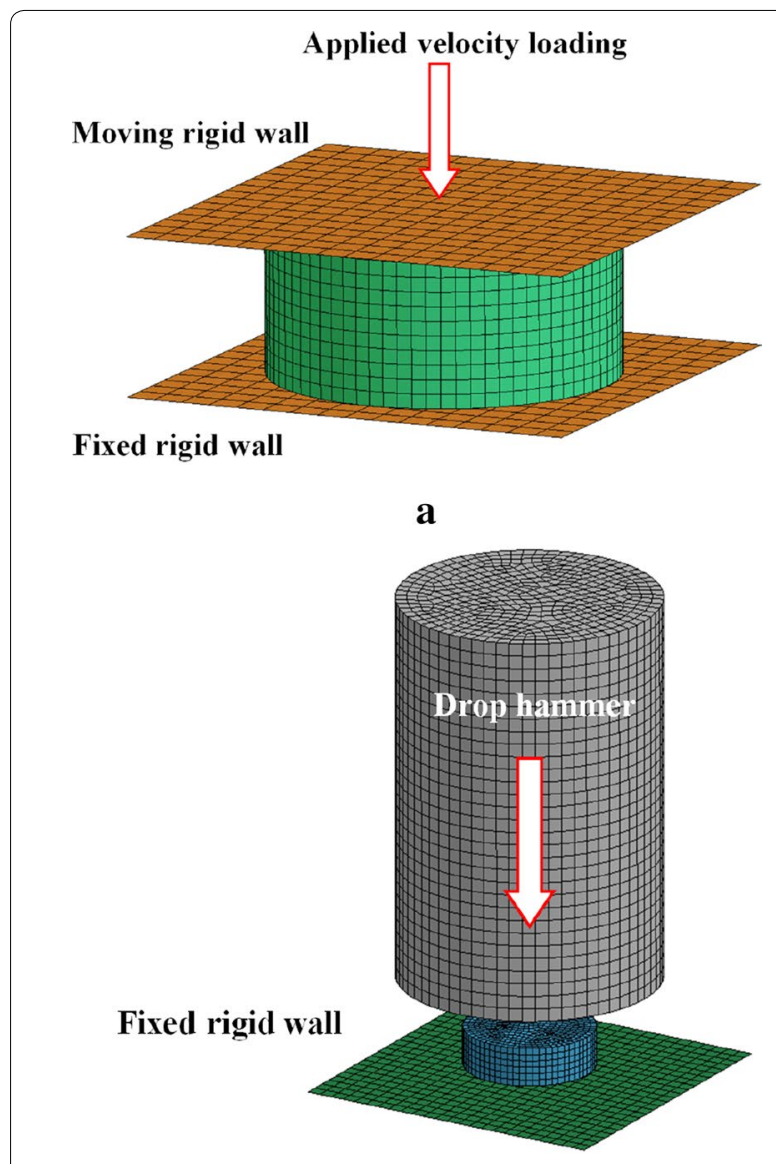

b

Figure 2 FE model for (a) quasi-static uniaxial compression and (b) compression impact tests

were fixed on the lower platen using special adhesive, which aimed to prevent the movement of the specimens and improve the test accuracy. The impact load and displacement were recorded by the load cell and displacement transducer when the specimens were crushed by the drop hammer. Being different with the quasi-static specimens, the height of the impact specimens is $7 \mathrm{~mm}$, and the diameter is $20 \mathrm{~mm}$. The FE model for numerical simulation has been developed in ANSYS/LS-DYNA, as shown in Figure 2(b).

In present study, totally three impact tests were carried out, and the force versus displacement curves of each test are presented in Figure 3(b). It can be found that the tests were reasonably reproducible. The results of numerical simulation have a satisfactory agreement with the test data, which indicated that the SRM model was sufficient accurate and can be effectively used for further studies.

\section{Numerical Simulations of the Plate Impact}

Due to numerous assumptions and the complexity of the calculations, experimental validations are needed for the FEA procedure to gain confidence in calculated results. In this section, the dynamic response of the aluminium alloy plate under the impact load by tire fragment was studied through numerical simulations. The main aim of the aluminium alloy plate impact study was to validate the numerical rubber model and the impact analysis method. It is important to validate the rubber model proposed with the impact test due to the large complexity of the rubber fragment. In addition, influences of various impact angles and velocities were discussed.

\subsection{FE Model of Aluminium Alloy Plate Impact}

Based on the experimental tests by Mines et al. [12], one FE model of aluminium alloy plate impact was set up for numerical simulations, as shown in Figure 4(a). The aluminium alloy plate has a thickness of $1.6 \mathrm{~mm}$. The Young's modulus, yield stress and Poisson ratio of the alloy plates are assumed to be $70 \mathrm{GPa}, 276 \mathrm{MPa}$ and 0.33 as plastic materials. It should be note that material failure was not considered in the numerical simulations. The reason was that rupture of alloy plate did not take place in experimental tests [12]. On the other hand, the main aim of present section was the validation of the tire fragment impact model but not a detailed model of alloy plate behavior. The rigid support condition of the plate is achieved through restraining $u=v=w=\theta_{x}=\theta_{y}=\theta_{z}=0$ DOF on the four sides. In addition, the fully integrated Belytschko-Tsai shell elements $5 \mathrm{~mm} \times 5 \mathrm{~mm}$ were chosen to model the plate.

According to relevant Refs. [28-31], the strain rate also has an obvious effect on the dynamic response of metallic materials. The Material Card, which represented as "MAT_PLASTIC_KINEMATIC in ANSYS/LS-DYNA was selected for the aluminium plate in this study. This model is used to define kinematic hardening plasticity and isotropic material. It is a very cost-effective material model which is available for solid and shell elements. In addition, the strain rate effect is taken into account by Cowper- Symonds model [32-34].

One idealised cuboid rubber fragment was considered, the dimension of this tire projectile was $20 \mathrm{~mm} \times 20$ $\mathrm{mm} \times 30 \mathrm{~mm}$, the average element size of the fragment FE model was set to be $2 \mathrm{~mm}$. More accurate results can be acquired by a finer size of the elements. It should be note that cords were not taken into account in this study, which can increase the rubber strength and stiffness. The reason for this was that the fragment of tire tread is usually considered as a rubber component without cords in many researches $[8,15]$. Using the keyword "INITIAL_ 

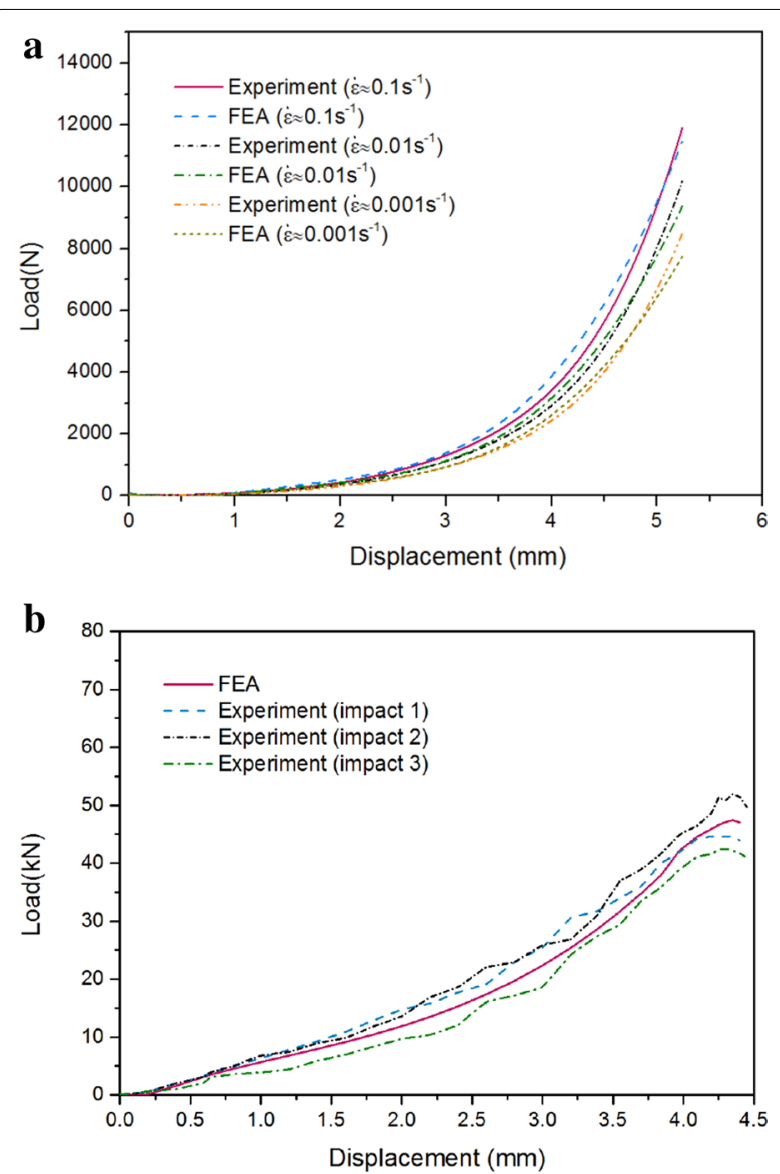

Figure 3 Comparison between the experimental and numerical results for (a) the quasi-static tests and (b) dynamic compression

VELOCITY_GENERATION, the impact velocity of the fragment model is achieved in ANSYS/LS-DYNA.

The contact condition between the rubber tire fragment and aluminium plate is also very important in the simulation of impacting. The large deformation of the rubber fragment during impact process and the dynamic property of the contact are complicated. The keyword "AUTOMATIC_CONTACT_ SURFACE _TO_SURFACE is one of the classic contact algorithms in ANSYS/ LS-DYNA, which provides an effective method to treat the interaction between separated parts [35-37]. By this contact algorithm, the interaction between the tire fragment and plate was calculated using a contact program, which is based on the penalty function with Coulomb formulation for defining the tangential interaction between the parts $[25,26]$. Coulomb friction is assumed in this model and hence the friction coefficient is the only parameter required ( $\mu=0.778$ according to the experimental tests [12]).

The aluminium alloy plate was placed at various angles with respect to the axes of the tire fragment. In present study, impact angles of $30^{\circ}, 50^{\circ}, 70^{\circ}$ and $90^{\circ}$ were considered, and the impact velocity varied between 20 and 135 $\mathrm{m} / \mathrm{s}$.

In experimental study [12], the aluminium alloy plate was connected with the supports by bolts on the four sides. The rubber specimens were fired using a powder gun, and the impact velocity can be adjusted by changing the internal pressure of the gun. In addition, four strain gauges (SG) were located in the region of impact and at a distance $100 \mathrm{~mm}$ from the centerline of the alloy plate in the impact direction, as shown in Figure 4(b). Strain gauge signals were amplified by differential amplifier and stored by a transient recorder. The experimental data from these strain gauges was used to validate the strain data from simulation in the directions of $x$ and $y$.

\subsection{Numerical Simulation of the Plate Impact}

The dynamic responses of the aluminium alloy plate and the cuboid fragment were shown in Figure 5 for various impact angle at several particular times (impact velocity $=135 \mathrm{~m} / \mathrm{s}$ ), it shows that both of the tire fragment and the alloy plate undergo large deformations. It is evident that deformation characteristics of alloy plate and the cuboid fragment are dependent on the impact angle when at certain velocity. The deflection of the alloy plate is increasing with the impact angle when lower than $90^{\circ}$. However, the sliding distance of the fragment before rebound, follows the expected tendency of decreasing with the impact angle increases. It can also be observed that the time when loss of contact occurs is dependent on the impact angle, larger the angle, earlier the fragment separates with the alloy plate.

According to the simulation results, it can be found that the plastic strain distributions on the alloy plate are obviously dependent on the impact angle, the plastic strain reach its maximum value when impact angle is equal of $90^{\circ}$. The increase of the impact angle not only affects the values of strains, but also their locations on the plate. The largest plastic strains were found at the impact area of the plate, plastic strains with lower magnitudes occur on the area along the edges of alloy plate when angle is larger than $50^{\circ}$.

\subsection{Comparison of Numerical Simulation and Experimental Data}

In this section, the numerically simulated strains on the alloy plate are compared with the test data at four different locations on the plate, as shown in Figure 6. All the curves exhibit a clear oscillatory behavior, which is a typical pattern in the impact scenario. According to the comparison between the simulation and experimental results, it can be observed that satisfactory agreements are obtained. It indicates that the proposed FE model 

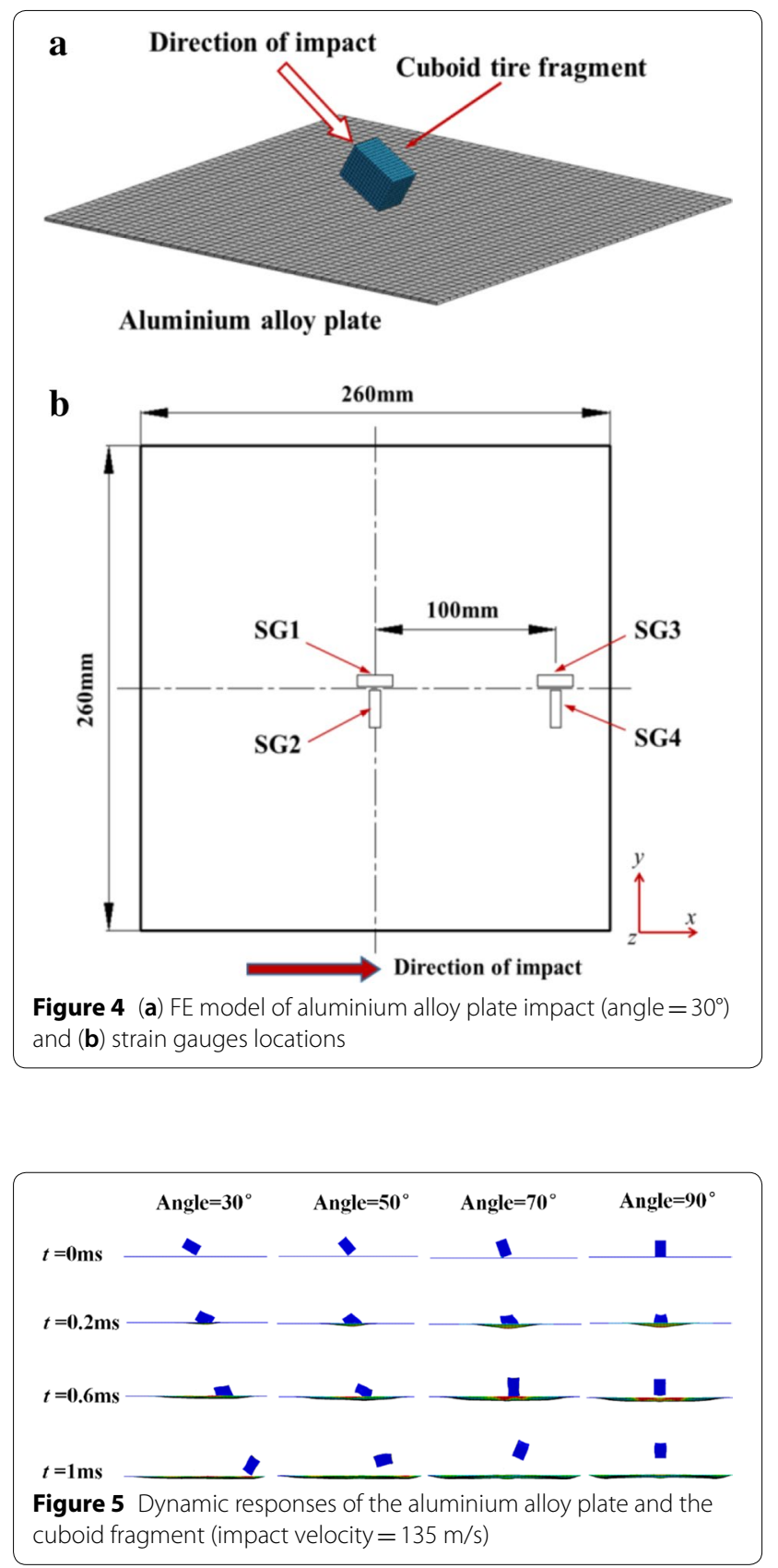

is reliable and can solve complex tire fragment impact problem. As shown in Figure 6(a) and (b), with impact angle is equal of $30^{\circ}$ and velocity is equal of $135 \mathrm{~m} / \mathrm{s}$, the peak response ratios of the experiment to the calculation are $115.2 \%$ and $106.7 \%$ for strain at SG1 and SG2, respectively. The peak response ratios of the experiment to the calculation are $123.9 \%$ and $102.1 \%$ at SG3 and SG4, respectively. Moreover, acceptable agreements between experimental and simulation results are also found in Figure 6(c) and (d).
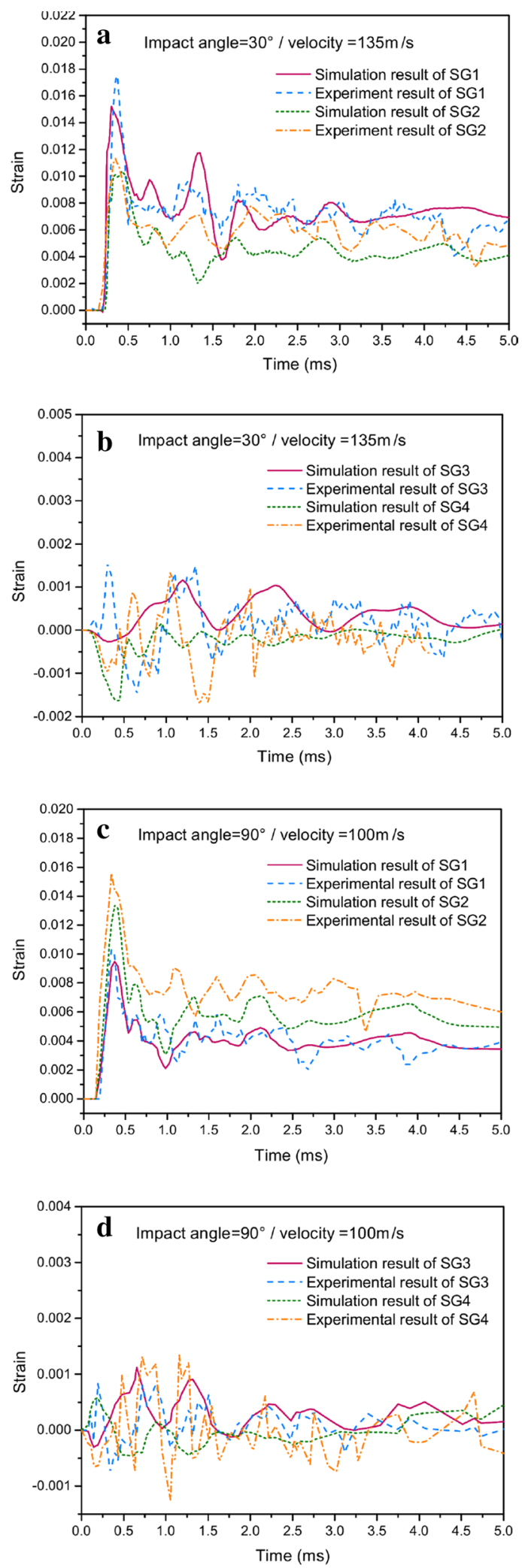

Figure 6 Comparisons of simulation and experimental results: (a) impact angle $=30^{\circ}$, velocity $=135 \mathrm{~m} / \mathrm{s}\left(\right.$ SG1-2), (b) impact angle $=30^{\circ}$, velocity $=135 \mathrm{~m} / \mathrm{s}(\mathrm{SG} 3-4),(\mathbf{c})$ impact angle $=90^{\circ}$, velocity $=100 \mathrm{~m} / \mathrm{s}$ $(\mathrm{SG} 1-2)$ and (d) impact angle $=90^{\circ}$, velocity $=100 \mathrm{~m} / \mathrm{s}(\mathrm{SG} 3-4)$ 
In addition, it should be noted that the strains of numerical simulation are little lower than experimental results. This phenomenon may be due to the fact that cords are not taken into account in present numerical simulations, which may increase the rubber strength and stiffness.

\subsection{Influences of Various Impact Angles and Velocities}

Table 1 lists the variations of maximum effective stress, deflection and impact load with velocities for angles of $30^{\circ}, 50^{\circ}, 70^{\circ}$, and $90^{\circ}$. It can be observed that the alloy plate will suffer the most serious impact influence when angle is equal to $90^{\circ}$. According to the simulations results, all values exhibit a similar increasing tendency with velocities and angles, however, the growth rates are not the same. It is found that the growth rates for different angles slowly decrease with the increasing of velocities. In addition, it should be noted that the growth rates of effective stress almost have the same variation tendency for different angles, as listed in Table 1.

The relationships between the kinetic energy of fragment and time for various angles are shown in Figure 7. It can be found that the kinetic energy exhibits an obvious decay tendency with the increase of angle. The curves rapidly decline until $0.25 \mathrm{~ms}$, and subsequently exhibit a clear oscillatory behavior between $0.25 \mathrm{~ms}$ and $0.75 \mathrm{~ms}$. Finally, after loss of contact between the fragment and plate, the curves become nearly flat with several small oscillations, which are due to that the tire fragment continues to vibrate and energy is dissipated in material damping. It should be noted that the relative proportion of these dissipated energies are dependent on impact

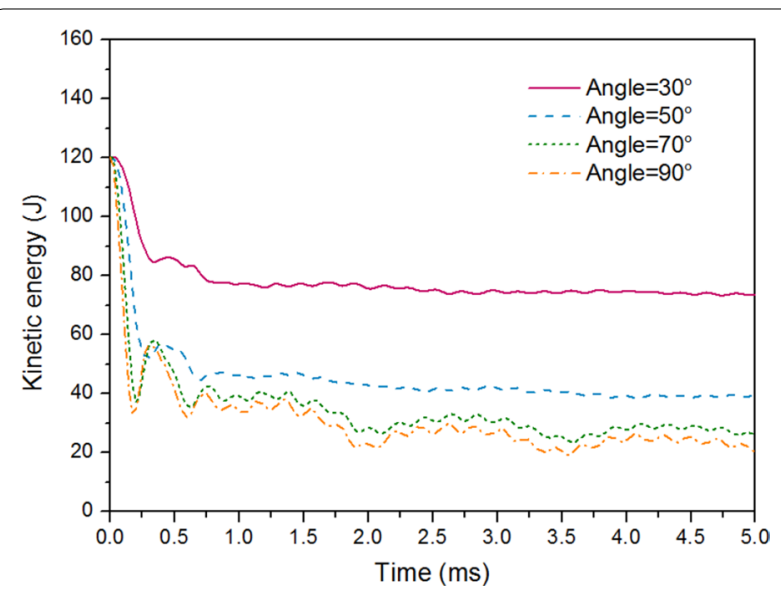

Figure 7 Kinetic energy versus time for different angles (impact velocity $=135 \mathrm{~m} / \mathrm{s}$ )

angles, larger the impact angle, more the dissipated energy.

\section{Extension of the Proposed Rubber Model to Larger Fragment}

In present section, the proposed rubber material model is used in numerical simulations of fuel tank access cover subjected to larger tire fragment impact. Various impact locations and access cover materials are considered.

4.1 FE Model of Large Tire Fragment and Fuel Access Cover According to the requirement of EASA [4], the tire fragment considered consist of 1 percent of the total tire mass, the impact load distributes over an area equal to 1.5 percent of the whole tire tread area. Based

Table 1 Maximum values of effective stress, deflection and impact load with various velocities and angles

\begin{tabular}{|c|c|c|c|c|c|c|c|}
\hline & \multirow[t]{2}{*}{ Impact angle $\left({ }^{\circ}\right)$} & \multicolumn{6}{|c|}{ Fragment velocity $(\mathrm{m} / \mathrm{s})$} \\
\hline & & 20 & 40 & 60 & 80 & 100 & 135 \\
\hline \multirow[t]{4}{*}{ Effective stress (MPa) } & 30 & 95 & 198.9 & 272 & 339.7 & 388 & 438.2 \\
\hline & 50 & 102 & 209 & 283 & 350 & 401 & 462 \\
\hline & 70 & 112 & 228 & 302 & 363 & 420 & 475 \\
\hline & 90 & 122 & 237 & 313 & 378 & 428 & 488 \\
\hline \multirow[t]{4}{*}{ Deflection (mm) } & 30 & 2.58 & 3.29 & 3.91 & 4.19 & 4.4 & 4.61 \\
\hline & 50 & 2.7 & 3.79 & 4.5 & 5.1 & 5.56 & 5.93 \\
\hline & 70 & 2.9 & 4.15 & 5.15 & 6.06 & 6.87 & 7.98 \\
\hline & 90 & 3.05 & 4.48 & 5.6 & 6.68 & 7.58 & 8.95 \\
\hline \multirow[t]{4}{*}{ Impact load (N) } & 30 & 1160 & 1387 & 2688 & 3990 & 4812 & 5638 \\
\hline & 50 & 1230 & 1691 & 3345 & 4780 & 6005 & 7610 \\
\hline & 70 & 1320 & 2150 & 3965 & 5780 & 7340 & 9500 \\
\hline & 90 & 1550 & 2852 & 4810 & 6808 & 8632 & 11205 \\
\hline
\end{tabular}


on airworthiness regulations, a fragment size of 39.9 $\mathrm{mm} \times 140.4 \mathrm{~mm} \times 140.4 \mathrm{~mm}$ proposed by Zhang et al. [15] is chosen for numerical simulation in present study. Consequently, it can be calculated that the mass of the rubber fragment is $0.784 \mathrm{~kg}$. In the FE model of rubber fragment, each solid element is $4 \mathrm{~mm} \times 4 \mathrm{~mm} \times 4 \mathrm{~mm}$.

The fragment is assumed to have a velocity equivalent to the tire speed when the aircraft take off (the additional velocity component caused by the release of tire pressure is not considered). According to Ref. [15], the impact velocity of $71.1 \mathrm{~m} / \mathrm{s}$ and impact angle of $40.5^{\circ}$ are chosen as initial condition in subsequent numerical calculation.

The FE model of fuel tank access cover has an elliptical shape, and the whole access cover is simulated with thin shell elements. The thickness of the shell element is 2.5 $\mathrm{mm}$. There are three ribs on the bottom surface, which can greatly strengthen the resistance of access cover to external impact load. The access cover and wing panel are connected by rivets on the boundary, and rivets are simulated by point constraints. In addition, it should be noted that the fixed constraint was chosen as boundary condition on four edges of the wing panel. To get accurate results, finer size for the shell elements is used in numerical simulations. On the other hand, the aluminium alloys of machining and precision casting are usually chosen as the material of fuel access cover [15], hence the two different materials are taken into account and compared in this study, the material properties for the two aluminium alloys are shown in Table 2.

Figure 8(a) shows the scenario of the fuel tank access cover subjected to large tire fragment impact. The initial distance between the fragment and access cover is $5 \mathrm{~mm}$ in FE model of impact. According to the study by Alexander et al. [8], the friction coefficient for the tire fragment to the wing panel contact interaction is set to 0.5 . The impact position has obvious influence on the dynamic characteristics of access cover with the same impact velocity, equivalent stress and damage degree of access cover vary from region to region [16]. Consequently, it is necessary to study the safety of access cover considering the influence of various impact regions. In present

Table 2 Material properties of the two aluminum alloys

\begin{tabular}{llllll}
\hline Material & $\begin{array}{l}\text { Density } \\
\left(\mathbf{k g} / \mathbf{m}^{\mathbf{3}}\right)\end{array}$ & $\begin{array}{l}\text { Young's } \\
\text { modulus } \\
(\mathbf{G P a})\end{array}$ & $\begin{array}{l}\text { Poisson } \\
\text { ratio }\end{array}$ & $\begin{array}{l}\text { Yield } \\
\text { stress } \\
(\mathbf{M P a})\end{array}$ & $\begin{array}{l}\text { Failure } \\
\text { strain }\end{array}$ \\
\hline $\begin{array}{l}\text { Aluminium } \\
\text { alloy by } \\
\text { machin- }\end{array}$ & 72 & 0.33 & 276 & 0.35 \\
ing & & & & \\
$\begin{array}{l}\text { Aluminium } \\
\text { alloy by } \\
\text { precision } \\
\text { casting }\end{array}$ & 70 & 0.33 & 272 & 0.08 \\
\hline
\end{tabular}

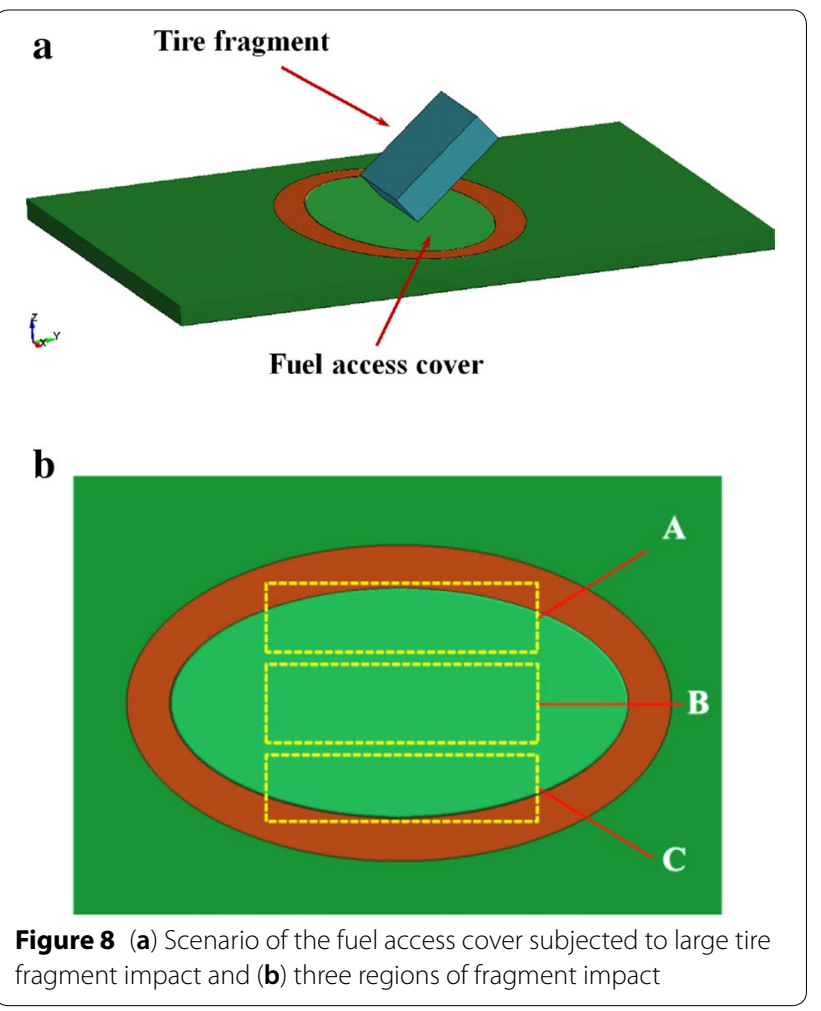

study, totally three impact modes with different impact regions (A, B and $\mathrm{C}$ ) are taken into account, as shown in Figure 8(b).

\subsection{Numerical Simulation of the Fuel Access Cover Impact}

Figure 9 shows the simulated sequential views of the tire fragment and the wing panel interaction process in mode B. It can be observed that the corner of the tire fragment nearest the plate obviously deforms after initial impact, and then the fragment slips along the wing panel. In the impact process, tire fragment will undergo great deformation and this behavior will result in an energy partition, which is rather different from a hard missile impact. In the case of a soft impact, a significant amount of the initial kinetic energy is transformed into the deformation energy of rubber fragment and large amount of energy is dissipated through the sliding contact [13].

Figure 10 shows the distributions of the plastic strains on the access cover with three modes. It can be found that the maximum plastic strain occurs on the middle rib with mode $B$. In mode $A$, the plastic strain which occurs mainly in the area of the initial impact, is much smaller than that in other two modes. Consequently, from the discussion above, it can be inferred that the mode $B$ may be the severest impact mode for the tire fragment impact which should be noticed. 


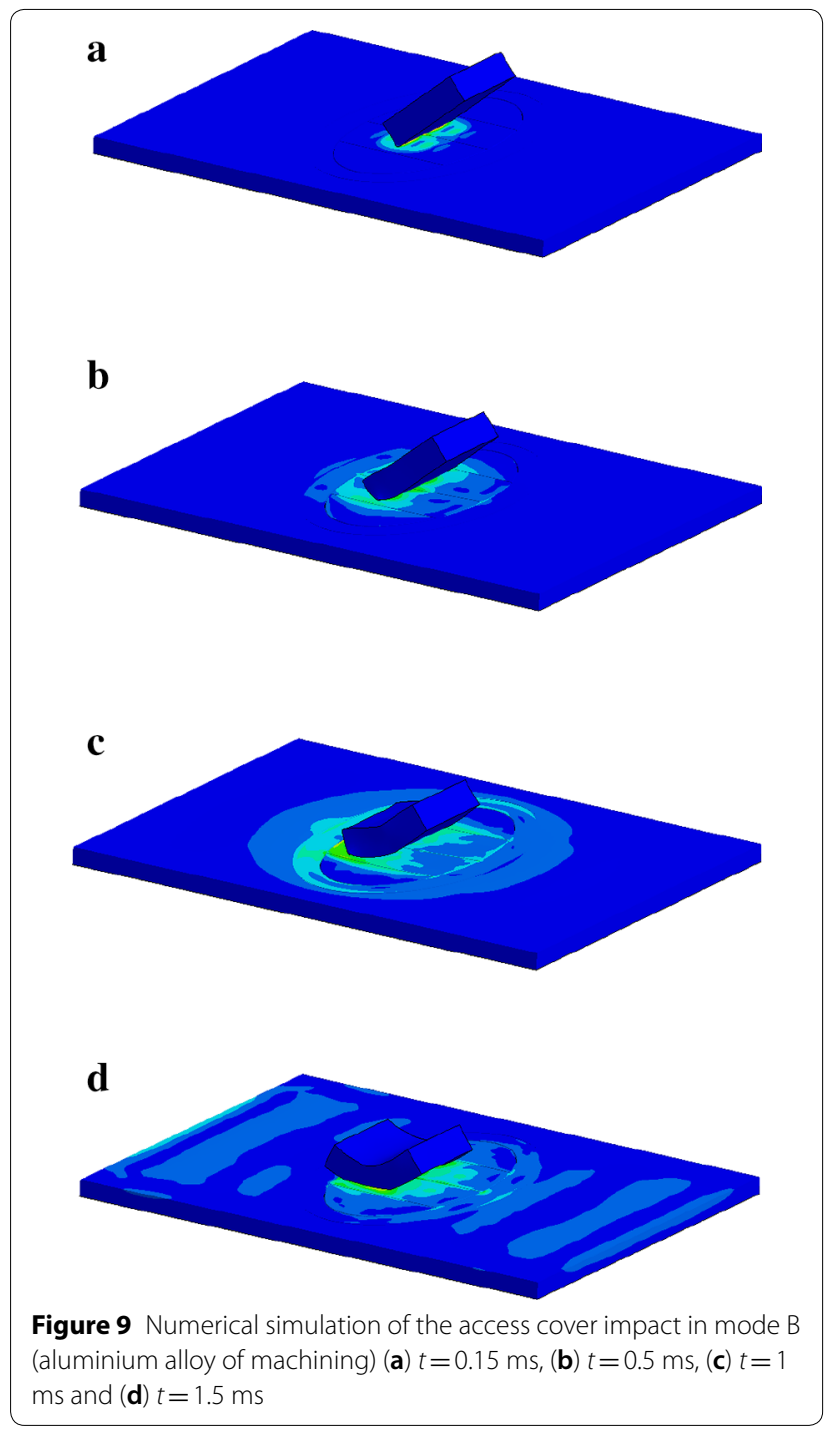

Figure 11 presents the equivalent stress distributions of access cover at various moments when impacted by the rubber fragment in mode $\mathrm{B}$. When time is equal to $0.125 \mathrm{~ms}$, the rubber fragment starts to contact with the top surface of the access cover. When time is equal to $0.45 \mathrm{~ms}$, the maximum stress value is found in the middle rib near the areas of the initial impact. It should be noted that no failure elements are found in the three modes for the aluminium alloy by machining, which indicates that the aluminium alloy by machining can bear the tire fragment impact and maintain the safety of flight with impact velocity of $71.1 \mathrm{~m} / \mathrm{s}$ and impact angle of $40.5^{\circ}$.

As can be seen from Table 3, the simulation results in three modes are listed. It can be seen that mode B has the maximum values of effective stress, plastic strain and
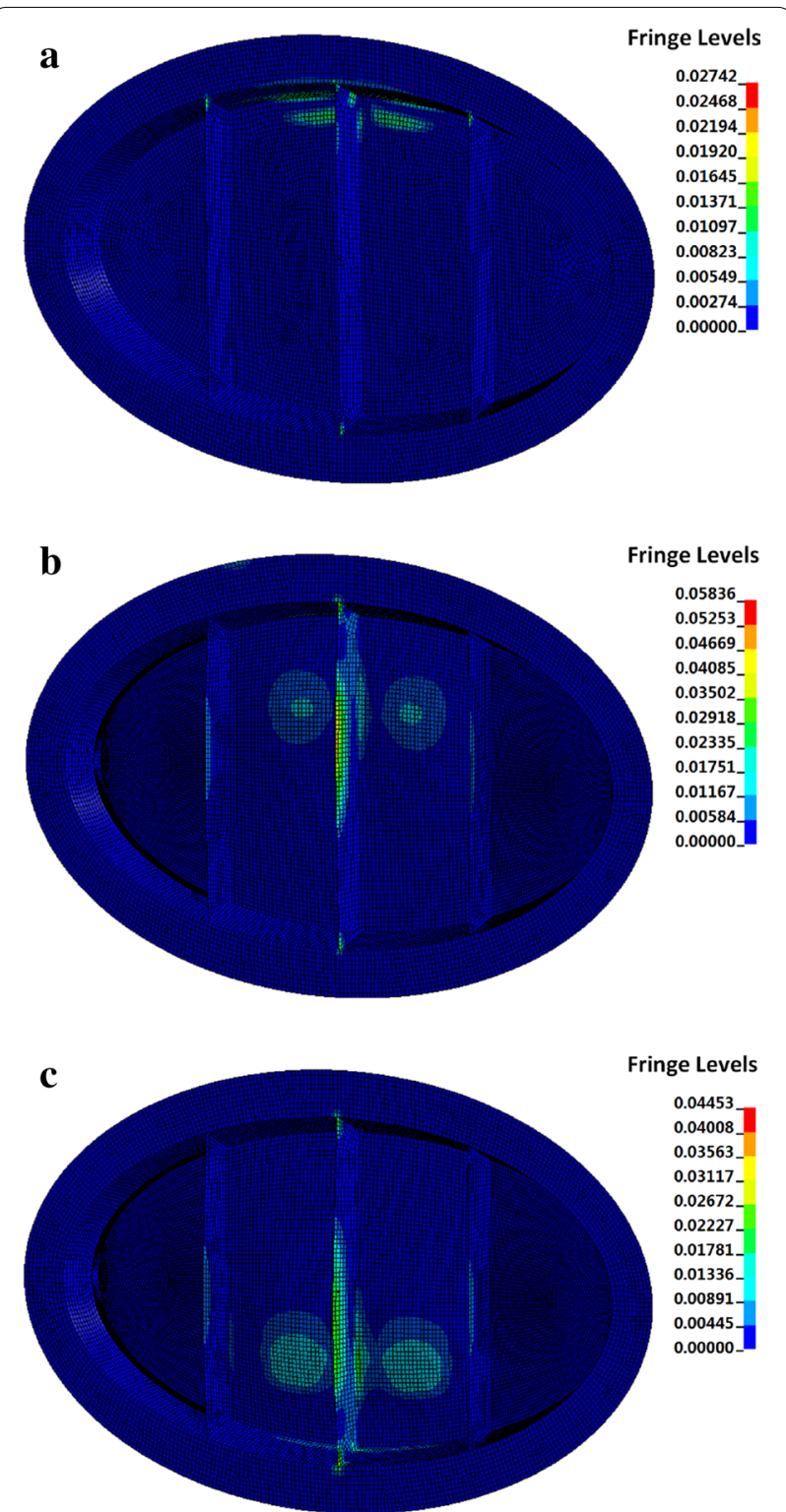

Figure 10 Residualt plastic strain distribution of access cover in (a) mode $A$, (b) mode B and (c) mode C (aluminium alloy by machining)

deflection, which indicate that the region $\mathrm{B}$ will suffer the severest impact by the tire fragment. However, the impact load in mode B is lower than other two modes, which may be due to the difference of structural stiffness in the three impact regions. Moreover, it can be inferred that more impact energy is absorbed by access cover during impact process with mode $\mathrm{B}$.

To compare the dynamic response of the two aluminium alloy in the tire fragment impact, the similar numercial calculations for aluminium alloy by precision casting are also conducted in present study. The simulations 


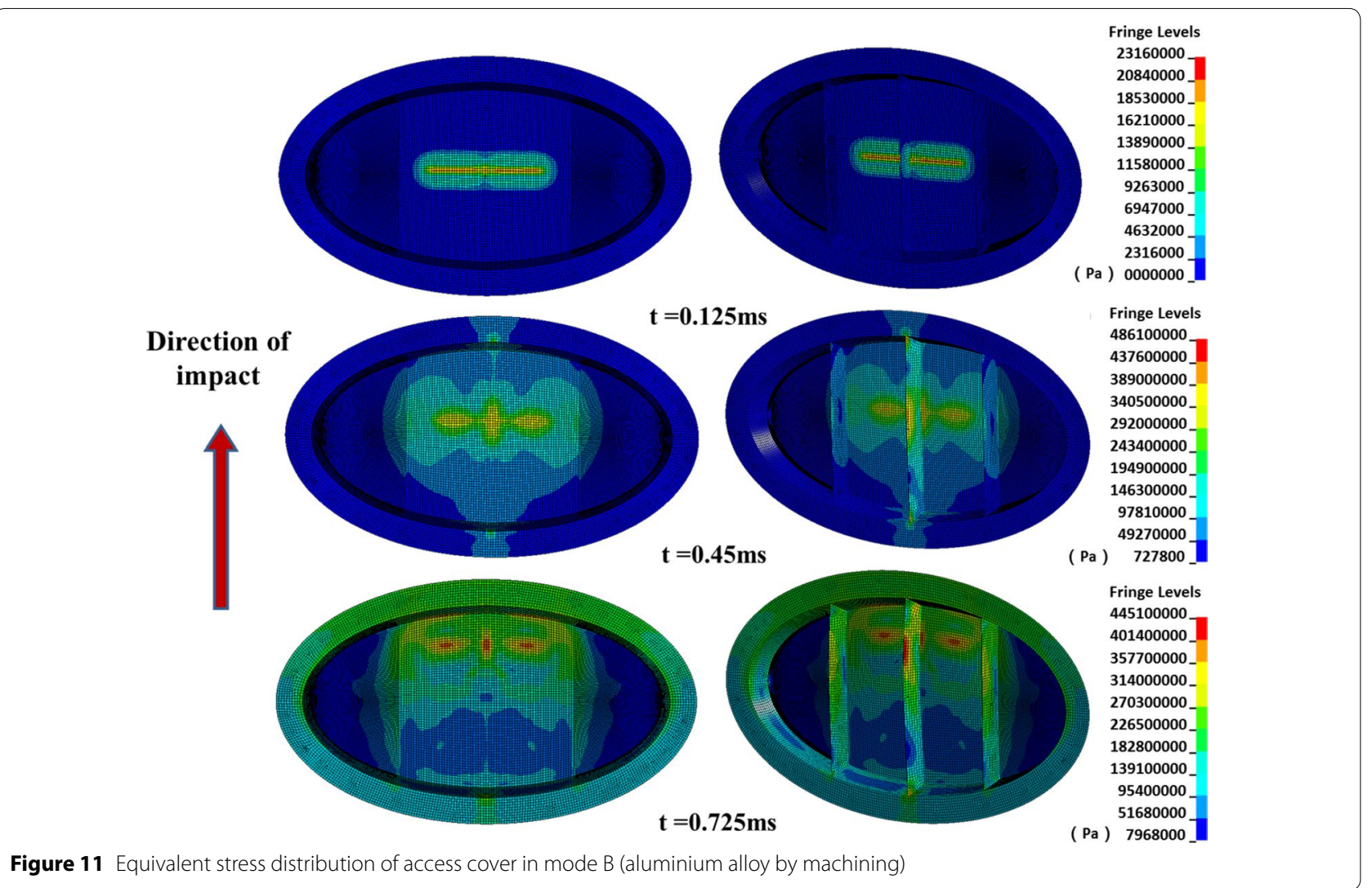

Table 3 Lists of the maximum values in three modes according to numercial simulationss (aluminium alloy by machining)

\begin{tabular}{lllll}
\hline & $\begin{array}{l}\text { Effective } \\
\text { stress (MPa) }\end{array}$ & Plastic strain & $\begin{array}{l}\text { Deflection } \\
(\mathbf{m m})\end{array}$ & $\begin{array}{l}\text { Impact load } \\
(\mathbf{k N})\end{array}$ \\
\hline Mode A & 418 & 0.027 & 17.8 & 35.8 \\
Mode B & 483 & 0.058 & 28.6 & 32.6 \\
Mode C & 439 & 0.045 & 25.3 & 39.6 \\
\hline
\end{tabular}

results shows that the aluminium alloy by precision casting will rupture in the tire fragment impact.

Figure 12 presents different failure patterns with corresponding impact modes, it can be observed that the access cover is seriously damaged and failure appears on the rib and the panel with the rubber fragment impacts. The opening size of the structural damage of access cover can be acquired. The failure patterns are similar between the mode $B$ and mode $C$, however, the initial rupture locations of them are different, which are near the corresponding areas of the initial impact. For the mode A, there is a smaller deformation in the initial impact region and tear appears only in the joints of panel and ribs,

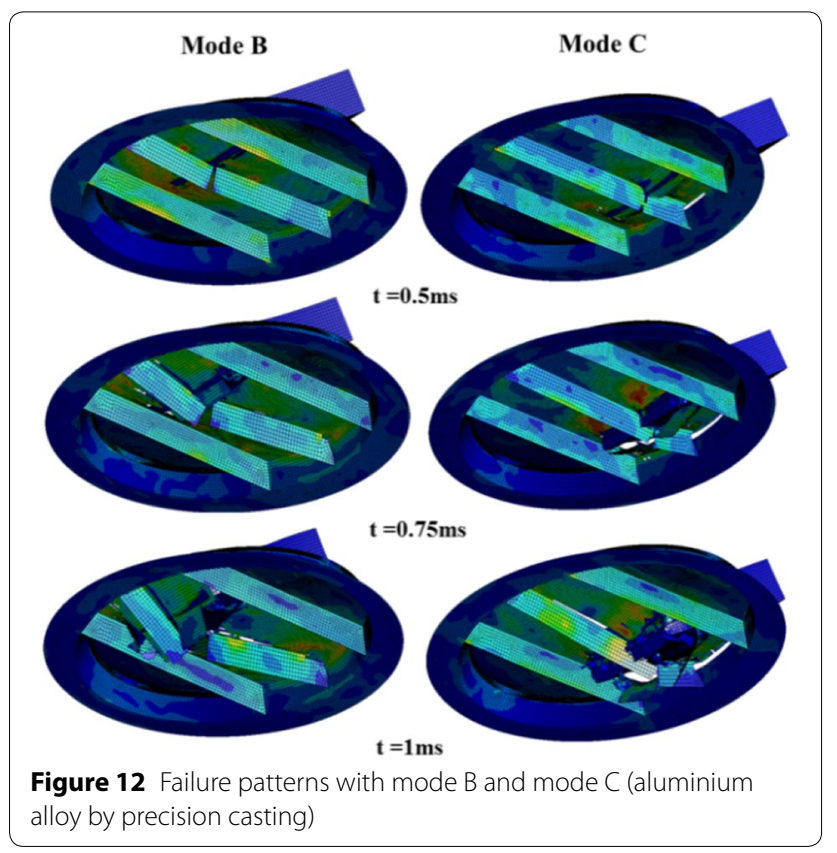

altogether 11 elements on the ribs are deleted according to the simulation result. 


\subsection{Discussion}

In present section, the safety of fuel tank access cover subjected to the large tire fragment impact with impact velocity of $71.1 \mathrm{~m} / \mathrm{s}$ and impact angle of $40.5^{\circ}$, is studied by numerical simulations. Altogether two different aluminium alloy materials and three impact regions are considered. The numerical simulations results indicate that the region $B$, which has the maximum values of stress and plastic strain, is vulnerable to occur damage with the tire fragment impact. On the other hand, as a typical material for fuel access cover, aluminium alloy by precision casting, is more likely to rupture in the large fragment impact, which may result in a fuel leakage. However, the aluminium alloy by machining can bear the tire fragment impact and maintain the safety of flight.

\section{Conclusions}

The main objective of the paper is to validate the safety of fuel access cover subjected to the large tire fragment impact. To acquire the hyperelastic characteristics of the rubber materials, several compression tests have been carried out. A simplified rubber model for finite element analysis and modelling approaches during high-speed impact are presented in this study. Material correlation and validation show that the chosen constitutive model is adequate for simulating the load cases ranging from quasi-static tests to dynamic tests. The dynamic response of the aluminium alloy plate under the impact load by tire fragment is studied through numerical simulations, which show satisfactory outcomes and close agreement with previous experimental results. Therefore, it can be inferred that the proposed numerical model is accurate and reliable for various cuboid tire fragment impact scenarios. Moreover, the influences of various impact angles and velocities are discussed. The simulation results show that the aluminium alloy will undergo the largest deformation when impact angle is equal to $90^{\circ}$.

Altogether two typical aluminium alloys for access cover and three impact regions are considered in this study. The simulation results indicate that aluminium alloy by precision casting is more likely to fail during the tire fragment impact, compared with the aluminium alloy by maching. Moreover, when subjected to tire fragment impact, the middle region of the access cover may be the most dangerous region, which has the maximum values of stress, plastic strain and deflection. It is essential that the safety analysis of the fuel access cover should be provided to the aircraft structural and systems designers, and will contribute to improve the level of safety in future aircraft designs.
Authors' Contributions

SY was in charge of the whole trial and wrote the manuscript; ZY provided guides in theory; XG and PW assisted with sampling and laboratory analyses.

All authors read and approved the final manuscript.

\section{Author Details}

1 Department of Engineering Mechanics, Henan University of Science and Technology, Luoyang 471023, China. ${ }^{2}$ School of Mechanics, Civil Engineering and Architecture, Northwestern Polytechnical University, Xi'an 710129, China.

\section{Authors' Information}

Shile Yao, born in 1984, is currently a lecturer at Department of Engineering Mechanics, Henan University of Science and Technology, China. He received his PhD degree from Northwestern Polytechnical University, China. His research interests include the harmfulness of aircraft tire blowout on typical structures and safety of aircraft tire.

Zhufeng Yue, born in 1965, is currently a professor at School of Mechanics, Civil Engineering and Architecture, Northwestern Polytechnical University, China. He received his PhD degree from Northwestern Polytechnical University, China. His research interests include the aircraft design theory and multidisciplinary design optimization of aircraft engine.

Xiaoliang Geng, born in 1976, is currently an associate professor at School of Mechanics, Civil Engineering and Architecture, Northwestern Polytechnical University, China. He received his PhD degree from Northwestern Polytechnical University, China. His research interests include the experimental mechanics and plastic mechanics of metal.

Peiyan Wang, born in 1984, is currently an associate professor at School of Mechanics, Civil Engineering and Architecture, Northwestern Polytechnical University, China. She received his PhD degree from Northwestern Polytechnical University, China. Her research interests include the mechanics of advanced composite materials.

Competing Interests

The authors declare that they have no competing interests

Funding

Supported by Research Fund for the Doctoral Program of Higher Education of China (Grant No. 20136102120031) and National Science Foundation of China (Grant No. 51805150).

\section{Publisher's Note}

Springer Nature remains neutral with regard to jurisdictional claims in published maps and institutional affiliations.

Received: 2 June 2017 Accepted: 18 February 2019

Published online: 26 February 2019

\section{References}

[1] S L Yao, Z F Yue, J M Zhang, et al. Safety assessment of protection cover under the blast pressure of aircraft tire blowout. Journal of Aerospace Engineering, 2018, 31(2): 04017103.

[2] H Guo, C Bastien, M Blundell, et al. Development of a detailed aircraft tyre finite element model for safety assessment. Materials and Design, 2014, 53: 902-909.

[3] S L Yao, Z F Yue, X L Geng, et al. An experimental investigation of pressure distribution in the flow field of aircraft radial tire blowout. Journal of Aerospace Engineering, 2017, 30(5): 04017031.

[4] European Aviation Safety Agency. CS-25 Amending decision on certification specifications for large aeroplanes. Cologne: European Aviation Safety Agency, 2013.

[5] F Zhang, J Zheng, M Li. Dynamic response of aircraft tire bursting debris under internal pressure. Acta Aeronautica Et Astronautica Sinica, 2017, 38(8): 134-143. (in Chinese)

[6] A Kohmura, S Futatsumori, N Yonemoto, et al. Optical fiber connected millimeter-wave radar for FOD detection on runway. IEEE 2013 Radar Conference, Nuremberg, Germany, Oct. 9-11, 2013: 41-44. 
[7] Federal Aviation Administration. 14CFR Part 25 Airworthiness standards: transport category airplanes. Washington: Federal Aviation Administration, 2009.

[8] A R Alexander, I R Vladimir, S K Sergey, et al. Numerical simulation of elastic-plastic deformation of aircraft fuel tank access cover impacted by tyre fragment. 9th European LS-DYNA Users Conference, Solihull, UK, 2013.

[9] L Ambriško, D Marasová, M Cehlár. Investigating the tension load of rubber composites by impact dynamic testing. Bulletin of Materials Science, 2017, 40(2): 281-287.

[10] R K Luo, W Wang, Q Xu, et al. An energy dissipation approach on complete loading-unloading and dynamic impact predictions with experimental verification for rubber anti-vibration component. Polymer Testing, 2017, 63: 314-322.

[11] M Andrejiova, A Grincova, D Marasova. Failure analysis of rubber composites under dynamic impact loading by logistic regression. Engineering Failure Analysis, 2018, 84: 311-319.

[12] R A W Mines, S Mckown, R S Birch. Impact of aircraft rubber tyre fragments on aluminium alloy plates: I-Experimental. International Journal of Impact Engineering, 2007, 34: 627-646.

[13] D Karagiozova, R A W Mines. Impact of aircraft rubber tyre fragments on aluminium alloy plates: II-Numerical simulation using LS-DYNA. International Journal of Impact Engineering, 2007, 34: 647-667.

[14] J O Hallquist. LS-DYNA Theory manual. Livermore: Livermore Publishing House, 2007.

[15] Y Q Zhang, Z Z Zhang. Civilian aircraft fuel tank access covers impact resistance by failed tire fragments characteristic analysis and test. Aircraft Design, 2013, 33(5): 35-38. (in Chinese)

[16] F S Wang, S Q Jia, Y Wang, et al. Impact response study on covering cap of aircraft big-size integral fuel tank. Applied Composite Materials, 2016, 23: 953-972.

[17] C Prus, R Vinuesa, P Schlatter, et al. Impact simulation and optimisation of elastic fuel tanks reinforced with exoskeleton for aerospace applications. International Journal of Crashworthiness, 2017, 22(3): 271-293.

[18] B Jiang. Effect of the microstructure of a filled rubber on its overall mechanical properties. Acta Mechanica, 2014, 225(4-5): 1121-1140.

[19] A K Kondé, I Rosu, F Lebon, et al. On the modeling of aircraft tire. Aerospace Science \& Technology, 2013, 27(1): 67-75.

[20] S L Yao, Z F Yue, X L Geng, et al. Dynamic response analysis of aluminium alloy thin plate under impact load by tire fragment. Hot Working Technology, 2017, 46(16): 49-52. (in Chinese)

[21] N Moslem, G Hossein. An efficient design tool based on FEM for evaluating effects of components properties and operating conditions on interaction of tire with rigid road. Journal of Central South University, 2015, 22(1): 189-195.
[22] P Baranowski, J Malachowski, J Janiszewski, et al. Detailed tyre FE modelling with multistage validation for dynamic analysis. Materials and Design, 2016, 96: 68-79.

[23] S L Yao, Z F Yue, X L Geng, et al. Finite element analysis of aircraft tire for safety assessment with CV and CPM methods. Multidiscipline Modeling in Materials \& Structures, 2017, 13(3): 501-518

[24] Livermore Software Technology Corporation. LS-DYNA Material models. Livermore: Livermore Publishing House, 2016.

[25] Livermore Software Technology Corporation. LS-DYNA Keyword manual. Livermore: Livermore Publishing House, 2016.

[26] Livermore Software Technology Corporation. LS-DYNA Theory manual. Livermore: Livermore Publishing House, 2016.

[27] American Society for Testing Material. D395 Standard test methods for rubber property - compression set. West Conshohocken: ASTM International, 2016.

[28] A K Rodriguez, G A Ayoub, B Mansoor, et al. Effect of strain rate and temperature on fracture of magnesium alloy AZ31B. Acta Materialia, 2016 112: 194-208.

[29] G Chen, Z H Ke, C Z Ren, J Li. Constitutive modeling for Ti-6al-4v alloy machining based on the SHPB tests and simulation. Chinese Journal of Mechanical Engineering, 2016, 29(5): 962-970.

[30] Y S Kim, S H Yang. Effect of plastic anisotropy on the formability of aluminum 6016-t4 sheet material. Chinese Journal of Mechanical Engineering, 2017, 30(3): 625-631.

[31] F K Cui, Y F Ling, J X Xue, et al. Work hardening behavior of 1020 steel during cold-beating simulation. Chinese Journal of Mechanical Engineering, 2017, 30(2): 321-331.

[32] C Hernandez, A Maranon, I A Ashcroft, et al. A computational determination of the Cowper-Symonds parameters from a single Taylor test. Applied Mathematical Modelling, 2013, 37(7): 4698-4708.

[33] B Liu, R Villavicencio, C G Soares. Experimental and numerical plastic response and failure of pre-notched transversely impacted beams. International Journal of Mechanical Sciences, 2013, 77(4): 314-332.

[34] Y Zhang, G Sun, XXu, et al. Multiobjective crashworthiness optimization of hollow and conical tubes for multiple load cases. Thin-Walled Structures, 2014, 82: 331-342.

[35] X Zhang, H Hao, G Ma. Dynamic material model of annealed soda-lime glass. International Journal of Impact Engineering, 2015, 77: 108-119.

[36] A Samiee, A V Amirkhizi, S Nemat. Numerical study of the effect of polyurea on the performance of steel plates under blast loads. Mechanics of Materials, 2013, 64(9): 1-10.

[37] S Jiang, M Huang, J W Zhan, et al. Numerical simulation on the SHPB test of argillaceous siltstone by using the LS-DYNA. Nonferrous Metals, 2016, 68(2): 54-58. (in Chinese)

\section{Submit your manuscript to a SpringerOpen ${ }^{\odot}$ journal and benefit from:}

- Convenient online submission

- Rigorous peer review

- Open access: articles freely available online

- High visibility within the field

- Retaining the copyright to your article

Submit your next manuscript at $\boldsymbol{\nabla}$ springeropen.com 